\title{
La necrópolis tardorromana de Toya. Peal de Becerro (Jaén)
}

\author{
Ma José Díaz García * \\ Vanessa Portero Fernández *
}

\begin{abstract}
RESUMEN
Se presenta un estudio sobre una nueva necrópolis Visigoda que se ha localizado en la localidad jiennense de Toya (Peal de Becerro). Se trata concretamente de 35 enterramientos de inhumación, que a pesar de no haber sido posible la excavación completa de la zona se advierte la envergadura del sitio, no solo por su enclave funerario, sino por las propias características de la necrópolis.
\end{abstract}

PALABRAS CLAVE: Necrópolis, Visigodos, inhumación.

\section{INTRODUCCIÓN}

El municipio de Peal de Becerro, y más concretamente la Cámara Sepulcral de Toya, constituye uno de los enclaves fundamentales dentro del proyecto "Viaje al tiempo de los Iberos".

Este proyecto contempla la puesta en valor de algunos de los asentamientos arqueológicos ibéricos de la provincia de Jaén, elegidos por su representatividad y particularidades.

Con la realización de esta propuesta se persigue acondicionar los asentamientos Ibéricos a través de diversas actuaciones, entre las que destacamos las de excavación, consolidación y adecuación arqueológica, creación y/o mejora

\begin{abstract}
This work is a study about a new necropolis Visigoda wich has been located in the jiennense town of Toya (Peal de Becerro). Exactly, it comprises of 35 buriels of interment and, although the total excavation of the area has not been posible, it is significant to highlight the importance of the place not only for its burial settlement but for the own features of the necropolis.
\end{abstract}

KEY WORDS: Necrópolis, Visigodos, interment.

de infraestructuras (vías de acceso, unidades de recepción, centros de interpretación...).

La construcción de un Centro de Recepción y una Playa de aparcamiento, como una de las medidas de adecuación fundamentales para la visita a la Cámara Sepulcral de Toya, trae aparejada la necesidad de una intervención arqueológica en las zonas aledañas a este conjunto funerario, con el objetivo de documentar los restos que puedan ser alterados con dichas intervenciones.

Con estos antecedentes y ante la presencia de restos arqueológicos en superficie, evidenciados nada más iniciarse los primeros trabajos de limpieza y, sobre todo, ante las noticias

* Arqueólogas profesionales 
de que éste pudo ser el lugar en el que, durante los años 50 se realizaron las intervenciones arqueológicas bajo la dirección de Doña Concepción Fernández Chicarro, era de esperar la aparición de una zona de necrópolisl. Estas Intervenciones arqueológica se efectuaron en dos campañas en las que se documentaron un total de 13 sepulturas Tardorromanas. Todas ellas estaban orientadas de $\mathrm{W}$ a $\mathrm{E}$, siendo la mayoría de ellas enterramientos dobles y varias presentaban restos humanos tanto en la parte de la cabecera como en la de los pies. Asimismo, estaban revestidas con losas mas o menos regulares unidas con lechado de cal y calzadas con cantos rodados. Las piedras de la cubierta estaban formadas por losas mucho más gruesas.

Los trabajos arqueológicos se han realizado en la parcela denominada Contracequia se localiza en el Término Municipal de Peal de Becerro, concretamente junto a la bifurcación existente en la carretera Peal de Becerro Hornos de Peal, y que permite acceder a la Cámara Sepulcral de Toya.

Geográficamente se encuentra ubicada en la zona inferior de la ladera sur del Cerro de la Horca, en cuya cima, está ubicada el citado espacio sepulcral. (Fig. I). Frente a este Cerro y separados por el Río Toya, afluente del Guadiana Menor, se localiza el Cerro del Castillo, en cuya ladera se emplazó la antigua ciudad ibero-romana de Tugia. Según las investigaciones realizadas, éste Cerro presenta una continua ocupación desde el Bronce Final hasta época Almohade. De ésta antigua ocupación, se conservan los restos de una Torre Visigoda (S. $\vee$ d. n. e) '. Por lo tanto el asentamiento, que sin lugar a dudas estuvo asociado a esta necrópolis, se localiza en este cerro. No obstante, resulta complicado definir las características de la ciudad Visigoda, ya que la dispersión cerámica perteneciente a los $\mathrm{S}$. VI y VII documentada es escasa, y esto, es algo que podría estar relacionado con el descenso de la población y que la ciudad había dejado de funcionar como tal, convirtiéndose en un núcleo rural, siguiendo un proceso similar al acaecido en la Campiña de Jaén, como se apunta en las investigaciones de V. Salvatierra y J. C Castillo.

Por su parte, los trabajos recientes han sido realizados entre los meses de junio y septiembre de 2002. El planteamiento de la excavación, consistió en la realización de 6 sondeos, todos con unas dimensiones iniciales de $3 \times 5$ metros, ampliándose, algunos de ellos, según las propias necesidades de la intervención. Gracias a estos trabajos, se documentaron 35 sepulturas, de las que sólo fue posible excavar un total de 27, así como una alberca romana y 7 fosas circulares del tipo "silo", cronológicamente anteriores a la necrópolis, posiblemente de época romana, aunque dada la ausencia de estratigrafía, no hemos podido determinar la posible relación de estas, con la alberca. No obstante, también cabe la posibilidad de que se trate de simples basureros.

\section{CARACTERÍSTICAS GENERALES}

Como ya hemos señalado, la necrópolis esta integrada por 35 sepulturas, excavadas en la base geológica y en la mayor parte de los casos, para un mejor acabado interno, la fosa se reviste mediante grandes lajas de piedra arenisca más o menos regulares. Por su parte, la cubierta de estas sepulturas, se realizó con grandes lajas planas también de piedra arenisca, escuadradas, y calzadas generalmente con pequeños cantos. Se da la particularidad en dos de las tumbas (6 y 18), en las que, las losas de la cubierta, además de estar calzadas por cantos, se documentan grandes fragmentos de tegulae. (Fig. 2)

Sin embargo merece especial atención, en lo referente a la cubierta, las sepulturas 5 y 8 (Lam. 3 y 4). En ambos casos se ha documentado una cubierta doble. La primera de ellas, I MONTILLA TORRES, I; PÉREZ ALVARADO, S. (2000) La Torre de Toya: Consideraciones acerca de su cronología. Revista de
Arqueología y Territorio Medieval No 5. Universidad de Jaén. 
la forman únicamente dos grandes lajas de arenisca, de grosor considerable (aproximadamente I 5 centímetros). La segunda, por el contrario, presenta el mismo sistema de cubierta que el resto de las sepulturas, y en ambos casos, la primera cubierta nunca se deposita directamente sobre la segunda.

Las dimensiones internas de las sepulturas oscilan entre 160 y 190 centímetros de largo, 40 y 60 centímetros de ancho, correspondiendo la parte más ancha a la cabecera. La profundidad media oscila en torno a los $40 \mathrm{~cm}$. Por el contrario, las dimensiones de la cubierta son de mayor tamaño.

Con respecto a la orientación, observamos cómo se ha producido un cambio respecto al tradicional romano $\mathrm{N}-\mathrm{S}$ por la de $\mathrm{E}-\mathrm{W}$ con 30 grados de desviación hacia el norte, en todas las sepulturas con la excepción de dos: la sepultura 10 que presenta una desviación de 20 grados y la sepultura 23 que presenta la orientación E-W.

En cuanto a la disposición de las inhumaciones que se han conservado en su posición original, señalar que fueron depositados en decúbito supino, aunque con ligeras variantes en lo que se refiere a la colocación de las extremidades. Generalmente con brazos y piernas extendidos. (Fig 3.)

Tipológicamente, atendiendo a la planta de las diferentes sepulturas, se ha realizado la siguiente diferenciación:

\begin{tabular}{|c|c|c|c|c|c|c|}
\hline \multirow[b]{2}{*}{$\begin{array}{l}\text { TIPOLOGÍA } \\
\text { FORMAL }\end{array}$} & \multicolumn{6}{|c|}{ VARIANTES SEGÚN EL REVESTIMIENTO } \\
\hline & $\begin{array}{l}\text { FOSA } \\
\text { SIMPLE }\end{array}$ & $\begin{array}{l}\text { LATERALES } \\
\text { MAYORES }\end{array}$ & $\begin{array}{l}\text { LATERALES } \\
\text { MAYORES } \\
\text { Y PIES }\end{array}$ & $\begin{array}{l}\text { LATERALES } \\
\text { MAYORES } \\
\text { Y CABECERO }\end{array}$ & $\begin{array}{c}\text { LATERALES } \\
\text { MAYORES, } \\
\text { CABECERO, PIES } \\
\text { Y SUELO }\end{array}$ & $\begin{array}{l}\text { LATERALES } \\
\text { MAYORES, } \\
\text { CABECERO } \\
\text { Y SUELO }\end{array}$ \\
\hline $\begin{array}{l}\text { RECTANGULAR } \\
\text { (TIPO I) }\end{array}$ & & 8 y 40 & & & 5 & \\
\hline $\begin{array}{l}\text { DE BAÑERA } \\
\text { (TIPO II) }\end{array}$ & & 1 y 2 & & & & \\
\hline $\begin{array}{c}\text { TRAPEZOIDAL } \\
\text { (TIPO III) }\end{array}$ & $\begin{array}{c}4,6,19^{2} \\
21,27 \text { y } 42\end{array}$ & $\begin{array}{c}9,17,18^{3}, \\
y 20\end{array}$ & 24 y $26^{4}$ & $7^{5}$ & $15^{6}$ y 23 & $10^{7}$ \\
\hline $\begin{array}{l}\text { INDETERMINADAS } \\
\text { (NO EXCAVADAS) }\end{array}$ & \multicolumn{6}{|c|}{$3,22,28,29,32,33,34,38$ y 44} \\
\hline $\begin{array}{c}\text { SEPULTURAS } \\
\text { DE NEONATOS } \\
\text { EN CERÁMICA } \\
\text { (TIPO IV) }\end{array}$ & \multicolumn{6}{|c|}{$11,12,13,14$ y 25} \\
\hline
\end{tabular}

2 Se localiza en el interior de la alberca de época romana que se ha documentado también en esta Intervención Arqueológica. Se trata de una fosa simple excavada en los niveles de colmatación que rellenan esta alberca, aunque utilizando el suelo de la misma para depositar las inhumaciones.

La cubierta está formada por 8 lajas de piedra arenisca escuadradas. Aparece hundida en su parte central, por lo que ambos lados de la cubierta aparecen elevados. La orientación es de W-E con $30^{\circ}$ de desviación hacia el norte.

En el interior de esta sepultura se han documentado dos inhumaciones infantiles, de sexo indeterminado. De uno de ellos, se ha conservado solamente los dos fémures, tibias y pelvis, mientras que del otro sólo han aparecido los dos fémures. Por esta razón, se desconoce su posición exacta, aunque probablemente estuvieran dispuestos decúbito supino.

En esta tumba, también se han encontrado numerosos clavos de hierro, que podrín formar parte de una cubierta o alguna estructura de madera tipo caja. 
Este último tipo de sepulturas, creadas para la inhumación de neonatos, están realizadas a modo de cista con ímbrices cerámicos de escaso tamaño. La base es un ímbrice de perfil en $U$, mientras que la cubierta la forman de uno a varios ímbrices con perfil en $U$ invertida. Es frecuente que en algunas de estas sepulturas se reproduzca la estructura de las tumbas de adultos, colocando pequeñas lajas a modo de cabecero y cantos rodados en los laterales mayores.

Algunos de los ímbrices de las cubiertas (sepultura 14), aparecen con decoración realizada con los dedos.

Las dimensiones de estas tumbas son escasas, no llegando a alcanzar los $50 \mathrm{~cm}$. de largo,

3 Fosa simple, excavada en la base geológica y posee una tipología trapezoidal, aunque como consecuencia del ensanchamiento que se produce en la parte central de la misma, podría corresponder con una tipología de codo, es decir, en la que los lados mayores de la planta rectangular se ensanchan por el centro, creando una especie de hexágono irregular.

La cubierta está formada por 10 grandes lajas de arenisca escuadradas, apareciendo un tanto hundida en la parte correspondiente con los pies de la sepultura.

La orientación es $\mathrm{W}-\mathrm{E}$ con $30^{\circ}$ de desviación hacia el norte.

En el interior de esta tumba, se han documentado la presencia de un individuo, dispuesto en posición decúbito supino con la cabeza girada hacia el norte y con brazos y piernas extendidos. Mide aproximadamente 1.60 metros de altura.

Esta sepultura presenta todos los tipos de reutilización que se han documentado en esta necrópolis y que se explican más adelante. De este modo, un primer individuo, fue apartado e introducido en una pequeña fosa excavada en el suelo de la sepultura para así dejar espacio suficiente y depositar a un nuevo individuo. Esta pequeña fosa se localiza en los pies de la sepultura y posee unas dimensiones de 0.65 metros de largo y 0.25 metros de ancho. Posteriormente, el segundo individuo depositado fue también apartado a la zona de los pies, para así depositar la siguiente inhumación. Por último, los restos de esta inhumación se extraen de la sepultura, se introduce otro individuo, que corresponde al único que se ha encontrado en su posición original (decúbito supino con los brazos y piernas extendidos) y una vez sellada la sepultura, los restos del individuo extraído, se colocan sobre la cubierta. No se ha documentado ningún tipo de ajuar personal o adorno ritual en el interior de la sepultura.

4 Está formada por una fosa simple excavada en la tierra y adscrita a una tipología trapezoidal.

La cubierta está formada por II lajas de piedra arenisca escuadradas y calzadas por pequeños cantos.

Los restos humanos documentados en el interior de la sepultura, se encuentran en mal estado de conservación, por lo que resulta imposible determinar sexo y tamaño de los individuos. Parece tratarse de una sepultura reutilizada, ya que los restos humanos documentados aparecen en una pequeña fosa localizada en la zona de los pies de la sepultura.

5 Se trata de una fosa simple excavada en la base geológica y se adscribe a una tipología trapezoidal.

La cubierta de la tumba está compuesta por 4 grandes lajas de piedra arenisca escuadradas y calzadas por lajas de menor tamaño, también de arenisca y por cantos rodados.

La orientación es $\mathrm{W}-\mathrm{E}$ con $30^{\circ}$ de desviación hacia el norte.

Se trata de una sepultura individual, ya que solamente se han documentado los restos de una inhumación, individuo que se depositó en posición decúbito supino, con la cabeza girada hacia el norte, las manos sobre la pelvis y las piernas estiradas.

Respecto al ajuar, sólo se ha documentado un elemento de adorno personal, concretamente una hebilla de cinturón de pequeño tamaño, realizada en bronce y de forma circular.

Destacar la aparición de clavos de hierro en el interior, relacionados, generalmente con elementos de sujeción y unión de objetos de mediano tamaño que se identifican con remaches. Podrían formar parte de pequeñas estructuras de madera que no se han conservado, tipo caja para introducir el difunto o bien una cubierta, que precedería a la de arenisca de las grandes lajas.

6 Se trata de una fosa excavada en la base geológica y se adscribe a una tipología trapezoidal.

La tumba aparece revestida con lajas de arenisca tanto en las paredes mayores, en el cabecero, en los pies, y en el suelo además posee cantos de pequeño tamaño que se utilizaron para calzar la totalidad del revestimiento. Del mismo modo, al igual que en la sepultura 10, el suelo también aparece revestido por grandes lajas de piedra, aglutinados por argamasa tipo mortero.

La cubierta está formada por 7 lajas de piedra arenisca escuadradas y 3 tipo tegula.

La orientación de ésta es también $W-E$, con $30^{\circ}$ de desviación hacia el norte.

En el interior de esta sepultura se ha documentado la inhumación de varios individuos, ya que en la parte correspondiente con los pies de la tumba aparecen numerosos fragmentos de hueso, sin conexión anatómica, que hacen pensar en la reutilización de la sepultura, ya que al llevar a cabo la segunda deposición, se apartan los huesos del primer individuo. En esta segunda inhumación, el individuo aparece dispuesto en posición decúbito supino con los brazos y piernas estirados. Mide aproximadamente 1.60 metros y. Se trata de una inhumación femenina adulta, ya que se han documentado, asociadas a este individuo, cuentas de collar de pasta vítrea de varios colores, así como aros de bronce del tipo pendientes.

7 Se trata de una fosa simple excavada en la base geológica y adscrita a una tipología trapezoidal.

La cubierta está formada por tres lajas de arenisca, ya que se observa la ausencia de varias lajas en la parte correspondiente a la cabecera de la misma, de este modo, lo que se documenta es la cara superior de algunas de las lajas que forman parte de las paredes de la sepultura.

La orientación de esta sepultura es W - E, aunque este es el único caso en el que la desviación es de $20^{\circ}$ hacia el norte. Los restos humanos documentados en su interior han sido algunos fragmentos sin conexión anatómica, por lo que resulta imposible determinar el sexo y la edad del / los individuos que la ocuparon. Dadas las pequeñas dimensiones de la sepultura, parece corresponder con el enterramiento de un individuo infantil. 
$20 \mathrm{~cm}$. de ancho y una profundidad que oscila entre los 10 y los $15 \mathrm{~cm}$. Se disponen también con una orientación NW-SE.

Estas sepulturas parecen estar asociadas a sepulturas adultas femeninas (sepultura 12 asociada a la adulta 7 ; sepultura 13 asociada a la 8), aunque esta posible relación deberá contrastarse a través de los estudios antropológicos. (Lam. 7.)

\section{EL RITUAL FUNERARIO}

El rito de enterramiento documentado en las necrópolis Tardoantiguas y de época Visigoda, es la inhumación, ya extendida en el mundo romano a partir del S. III. La sustitución del ritual de incineración por el de inhumación, se produce de forma gradual, según algunos autores, por influencia del Cristianismo y según otros, debido, a que este rito nunca fue abandonado por los romanos. Sea como fuere, la inhumación se extiende por todo occidente a partir del S. IV d. n. e, constituyendo esta necrópolis un ejemplo más.

A partir del S. IV d. n. e, las tumbas sufren un cambio de orientación. Se sustituye el tradicional romano $\mathrm{N}-\mathrm{S}$ por $\mathrm{E}-\mathrm{W}$, que se aprecia en los territorios que los Visigodos ocupan. Este cambio no tiene porqué ser indicativo de una modificación en el ritual, pero si es exponente de influencias foráneas. La nueva orientación estaría directamente relacionada, según algunos autores, con la irrupción del Cristianismo en occidente, ya que la cabeza del individuo dirigida al E, le permitiría contemplar la salida del sol. Dentro de este cambio de orientación, se encuadraría la necrópolis Visigoda de Toya, ya que todas las sepulturas presentan una orientación NW-SE.

En aquellas sepulturas en las que hemos documentado restos humanos, los individuos se depositaron en decúbito supino, generalmente con brazos y piernas extendidas. No obstante existen algunos casos, como en las sepulturas $N^{0} 7$ y 21 , donde la disposición de las manos aparece sobre la pelvis. Junto a ellos, hemos documentado un total de 9 sepulturas que no conservaban ningún resto humano en su interior ( $N^{\circ} 4,5,10,11,12,13,14,25$ y 27), posiblemente porque no han soportado la acidez natural del terreno.

Por otro lado, la reutilización de las sepulturas es otro de los aspectos que conforman el ritual funerario, hecho que es una constante durante todo este periodo. En nuestro caso, la reutilización se produce de diversas formas:

- La primera de ellas, se ejecuta retirando los restos humanos más antiguos hacia la parte E de la sepultura, coincidiendo con los pies de la misma, lo que les permitió dejar el espacio suficiente para depositar la nueva inhumación.

- Otra forma de reutilización se produce excavando una pequeña fosa en el lecho original de la sepultura, y a continuación se introduce en ella, el mayor número posible de restos (Sepulturas 9 y 18). (Lam. 6.)

- Por último, constatamos también algunos casos en los que la reutilización se realizaba extrayendo los huesos de la sepultura para colocarlos sobre la cubierta de la misma. Este hecho se produciría en aquellas sepulturas que habían sido reutilizadas en numerosas ocasiones. (Sepultura 7 y 18).

No obstante, cabe señalar que el primer tipo de reutilización es el más frecuente en esta necrópolis, aunque existe un caso peculiar, concretamente el de la sepultura $N^{\circ} 18$, donde se reúnen los tres tipos. De este modo, la primera inhumación fue apartada e introducida en una pequeña fosa excavada en el suelo de la sepultura, para así dejar espacio suficiente y depositar a una nueva inhumación. Esta pequeña fosa, se localiza a los pies de la sepultura, y posee unas dimensiones de $65 \times 25$ centímetros. Posteriormente, la segunda inhumación fue también apartada a la zona de los pies, para así depositar el nuevo cadáver. Finalmente, estos restos humanos fueron extraídos de la sepultura para depositar un nuevo individuo, que corresponde con el único que se ha encontrado en su posición original (Decúbito supino con brazos y piernas extendidas) pero una vez sellada la sepultura, los restos extraídos se colocan sobre la cubierta. 


\section{LOS AJUARES}

Un aspecto importante de las sepulturas lo constituye el ajuar, aunque la mayor parte de los elementos documentados en el interior de las sepulturas los hemos considerado objetos de adorno personal, por tratarse de cuentas de collar, realizadas todas ellas en pasta vítrea, de diversos colores y formas (Lam. I5.) Junto a ellas, se exhumaron también brazaletes, pulseras, pendientes, hebilla de cinturón, alfiler..., todos ellos (V. Lam. 13 y 14) realizados en bronce y con formas bastantes simples, sin decoración apreciable. Solamente se ha documentado un depósito ritual en la Sepultura 6 , consistente en una jarrita de un asa, realizada a torno, de pasta más o menos depurada y de color claro por su cocción oxidante, con borde circular y base plana, que fue depositada en la zona de la cabecera, concretamente entre el cráneo y el hombro izquierdo, sin embargo, dadas las reducidas dimensiones de dicha sepultura, es posible que se trate de una tumba infantil. (Lam. 12.) Lo que se corresponde con una de las constantes más comunes llevadas a cabo en las necrópolis rurales Tardoantiguas de Andalucía 8 .

\section{CONCLUSIONES FINALES}

Por Antigüedad Tardía entendemos el periodo que se extiende desde los últimos años del Imperio Romano hasta el establecimiento de un nuevo orden, desde el punto de vista político, social, económico y religioso, y que supone el establecimiento de un nueva cultura en la Península: La Visigoda, cuya influencia será distinta dependiendo de la zona geográfica.

La información aportada por la arqueología al conocimiento del mundo funerario rural de la Tardoantiguedad y de época visigoda en Andalucía, resulta deficiente, debido al escaso número de intervenciones arqueológicas, que además son de carácter de urgencia.

Aunque en esta necrópolis no se ha podido documentar, cabe la posibilidad de que también en ella se efectuaran pequeñas agrupaciones de sepulturas, por motivos espaciales, temporales o familiares como ocurre en la Necrópolis de el Ruedo (Almedinilla, Córdoba). Junto a ellos así como espacios de distribución y organización del tránsito de la misma necrópolis, previamente establecidos. Así mismo cabe la posibilidad de que las sepulturas se estructuraran de forma ordenada componiendo hileras, a modo de calles, para así, permitir la libre circulación dentro del área funeraria.

Por otro lado, junto a esta necrópolis, además se han documentado otros elementos arqueológicos de gran importancia. Nos referimos a los restos de una alberca adscrita a un periodo romano. Para la construcción de esta alberca, se realizó una fosa en la base geológica. Los muros se construyeron con Opus Caementicium y se revistieron, en su parte interna con Opus Signinum, que además tendría la función de impermeabilizarla. Posee tanto en las cuatro esquinas como en la parte inferior interna un elemento constructivo muy frecuente en este tipo de construcciones, como es la Media Caña. (Fig 4 y Lam. 9)

Esta estructura posee dos elementos relevantes: un desagüe formado por una tubería de plomo y un rebosadero, ambos con una técnica constructiva bastante cuidada (Lams. I0 y II). Por esta razón, se ha pensado que no se puede tratar de un elemento aislado en el medio rural, sino que pueda estar asociada a una Villa. Esta alberca se encontraba abandonada en época Visigoda, por lo que sobre ella, se emplazaron varias sepulturas en su interior. Con este fin, las fosas rompen los niveles de colmatación de la misma, e incluso

8 CHOCLAN SABINA C; SERRANO PEÑA, J. L (1989): Excavación de Urgencia en el Polígono Industrial de Lopera (Jaén). Anuario Arqueológico de Andalucía. 
en la sepultura 19 se utiliza el suelo de la alberca como base sobre la que se deposita la inhumación.

En este periodo es muy frecuente que estas necrópolis tuvieran asociadas espacios de reunión del tipo Basilica y que, generalmente, eran Villae reutilizadas y transformadas para estas funciones, como es el caso de la documentada en la Venta de Guarromán (Toro y Serrano), donde se habla de la posible reutilización de la Villa como basilica o el caso de Almedinilla en Córdoba donde se habla de la posibilidad de que la necrópolis estuviese relacionada con la servidumbre que dependía directamente de la Villa, excavada en las inmediaciones de la necrópolis ${ }^{9}$. También cabe la posibilidad de que este tipo de necrópolis estuviesen estructuradas en torno a caminos o importantes vías de comunicación.

Todo ello son hipótesis con las que se pretende poner en relación la necrópolis con la alberca, documentados ambos en esta parcela, y cuyos resultados quedan sesgados como consecuencia de la falta de medios financieros para continuar con la Intervención Arqueológica que permitiría, así determinar todas estas incógnitas.

Por último, tipológicamente, la necrópolis Visigoda de Toya, se puede adscribir a un periodo temporal bastante amplio (S. II-VII d. n. e) por paralelos con otras necrópolis como la de la Virgen de la Encina (CHOCLAN Y PÉREZ BAREAS, 1988 e. P) que se adscribe a un periodo bajoimperial o a la necrópolis de las Delicias (TORO Y RAMOS, 1985; 14 -49), adscrita al periodo Visigodo. En el caso de esta necrópolis, nos inclinamos por una fechación en torno a los S. IV-VII, tanto por la tipología general de la necrópolis, como por el ajuar documentado.

\section{BIBLIOGRAFÍA}

ALONSO SÁNCHEZ, Ma. A. (1976): "Necrópolis de El Cerro de las Losas en el Espartal (Madrid)". Noticiario Arqueológico Hispánico. 4.

CARMONA BERENGUER, S. 1998; Mundo funerario rural en la Andalucía Tardoantigua y de época Visigoda. La necrópolis de El Ruedo (Almedinilla, Córdoba). Diputación de Córdoba.

CASTILLO ARMENTEROS, J. C (1998): La Campiña en época Emiral (s. VIII - X). Pp. I58 - 167, 218, 262 - 263. Servicio de Publicaciones e Intercambio Científico. Universidad de Jaén.

CHAMOSO LAMAS, M Y FIGUERA VALVERDE, J. (1976): "Excavaciones Arqueológicas En la Iglesia y Atrio de San Bartolomé de Rebordanes; de Tuy (Pontevedra)". Noticiario Arqueológico Hispánico. 4.

CHOCLÁN, C; PÉREZ, C (1988): Prospección con Sondeos Estratigráficos en Ermita Virgen de la Encina. (Baños de la Encina, Jaén). Informe Preliminar. "A.A.A.III, I48-I56.

CHOCLAN SABINA C; SERRANO PEÑA, J. L (1989): Excavación de Urgencia en el Polígono Industrial de Lopera (Jaén). Anuario Arqueológico de Andalucía.

FERNÁNDEZ CHICARRO, C. 1954; "Viaje de Prospección arqueológica por el término de Peal de Becerro". Boletín de Estudios Jiennenses.

FERNÁNDEZ CHICARRO, C.1957; "Avance sobre recientes prospecciones arqueológicas en Castellar de Santisteban y Peal de Becerro". Boletín de Estudios Jiennenses.

FERNÁNDEZ GALIANO RUIZ, D. (1976): "Marco Arqueológico Visigodo de la Zona de Alcalá de Henares". Noticiario Arqueológico Hispano. 4.

IZQUIERDO BENITO, R. (1977); "Ensayo de una sistematización hipológica de la cerámica de necrópolis de época visigoda". Revista de Archivos, Bibliotecas y Museos. Madrid.

IZQUIERDO BENITO, R. (1977); "Cerámica de necrópolis de época visigoda del Museo Arqueológico Nacional". Revista de Archivos, Bibliotecas y Museos. Madrid.

ALMAGRO BASCH, M. (1975): La Necrópolis Hispano Visigoda de Segobriga. Saelices (Cuenca). Excavaciones Arqueológicas en España No 84.

SERRANO PEÑA J. L Y CASTILLO ARMENTEROS J. C. (2000) "Las necrópolis medievales de Marroquíes Bajos (Jaén). Avance de las investigaciones Arqueológicas". Revista de Arqueología y Territorio Medieval. Universidad de Jaèn.

9 CARMONA BERENGUER, S. 1998; Mundo funerario rural en la Andalucía Tardoantigua y de época Visigoda. La necrópolis de El Ruedo (Almedinilla, Córdoba). Diputación de Córdoba 
SERRANO PEÑA, J. L; SÁNCHEZ NAVARRO, CY GÓMEZ DE TORO, E. Informe de excavación Arqueológica de urgencia en el yacimiento de la Venta, Guarromán, Jaén.

SERRANO, E; ATENCIA, R. 1986; La necrópolis de época visigoda de "El Tesorillo"; Actas del I Congreso de Arqueología Medieval española. Tomo II, n8. Zaragoza.

SALVATIERRA CUENCA, V; GARCIA GRANADOS I. A; JABALOY SÁNCHEZ M ${ }^{\text {a }}$. Y Y MORENO HONORATO Ma A.: Necrópolis Medievales I: Baza. Museo Arqueológico de Granada.
TOVAR LLORENTE, A; SUPIOT, I Y PÉREZ VILLANUEVA, J. (1932 - 1933): "Avance de estudio sobre la necrópolis visigoda de Piña de Esgueva". Seminario de Estudios de Arte y Arqueología de la Universidad de Valladolid.

V. V. A. A (|98I); "Necrópolis tardorromana en Valderrubio (Granada)". Cuadernos de Prehistoria de la Universidad de Granada. № 6. 


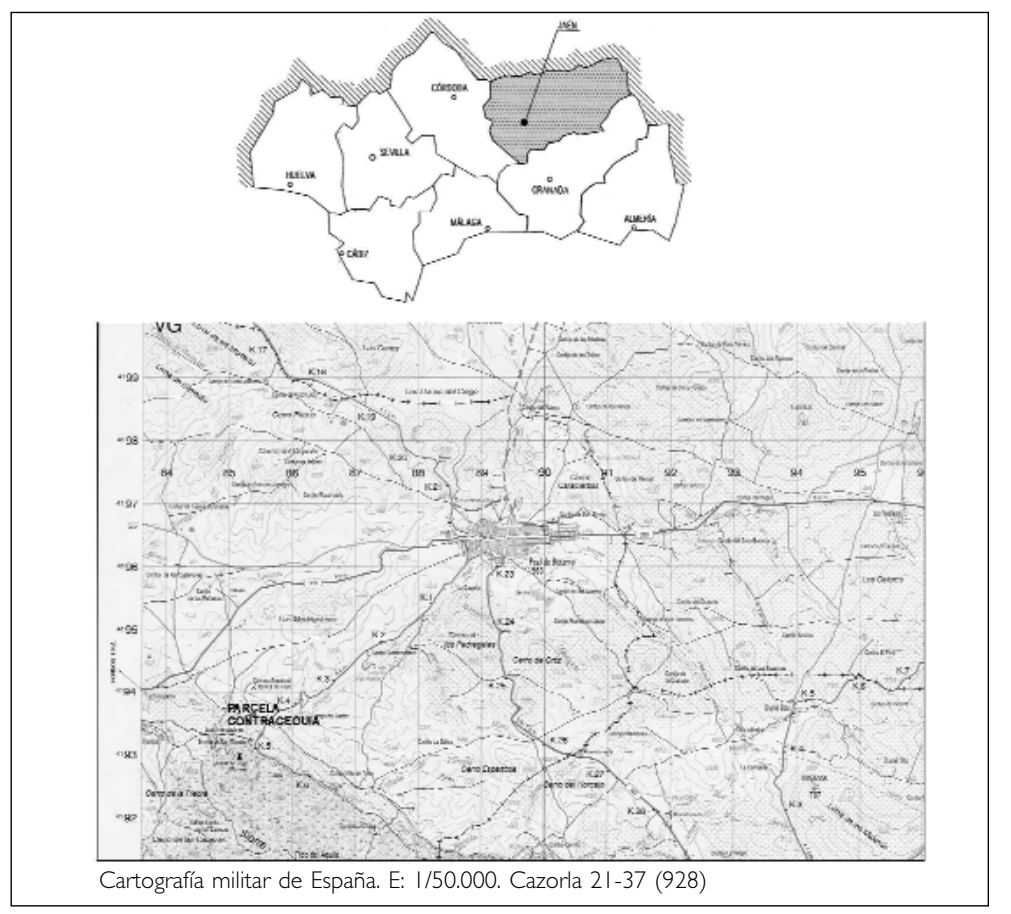

Fig. I. Situación de la parcela

Fig. 2. Corte 7. Planta I. Cubierta de las sepulturas

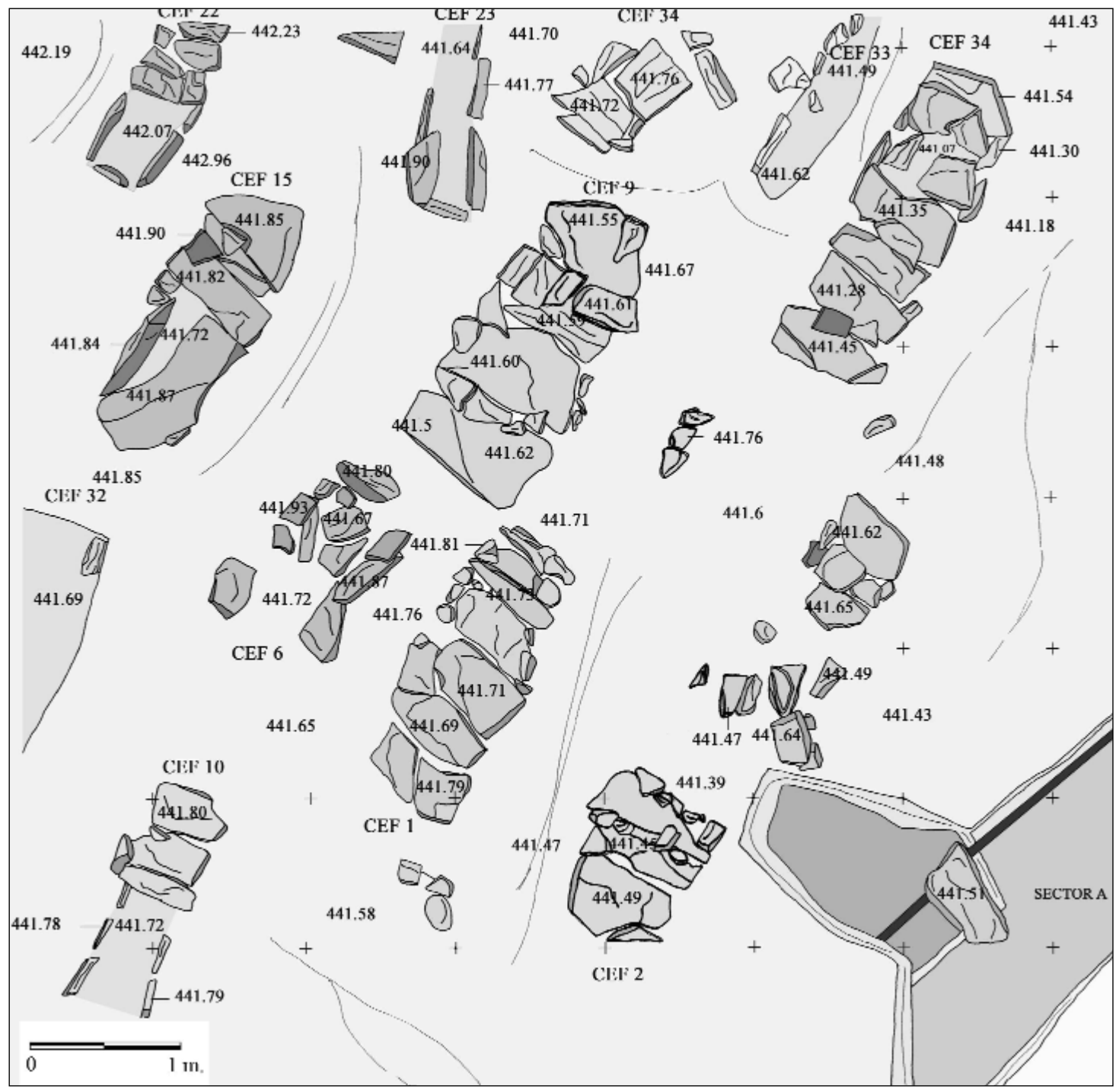




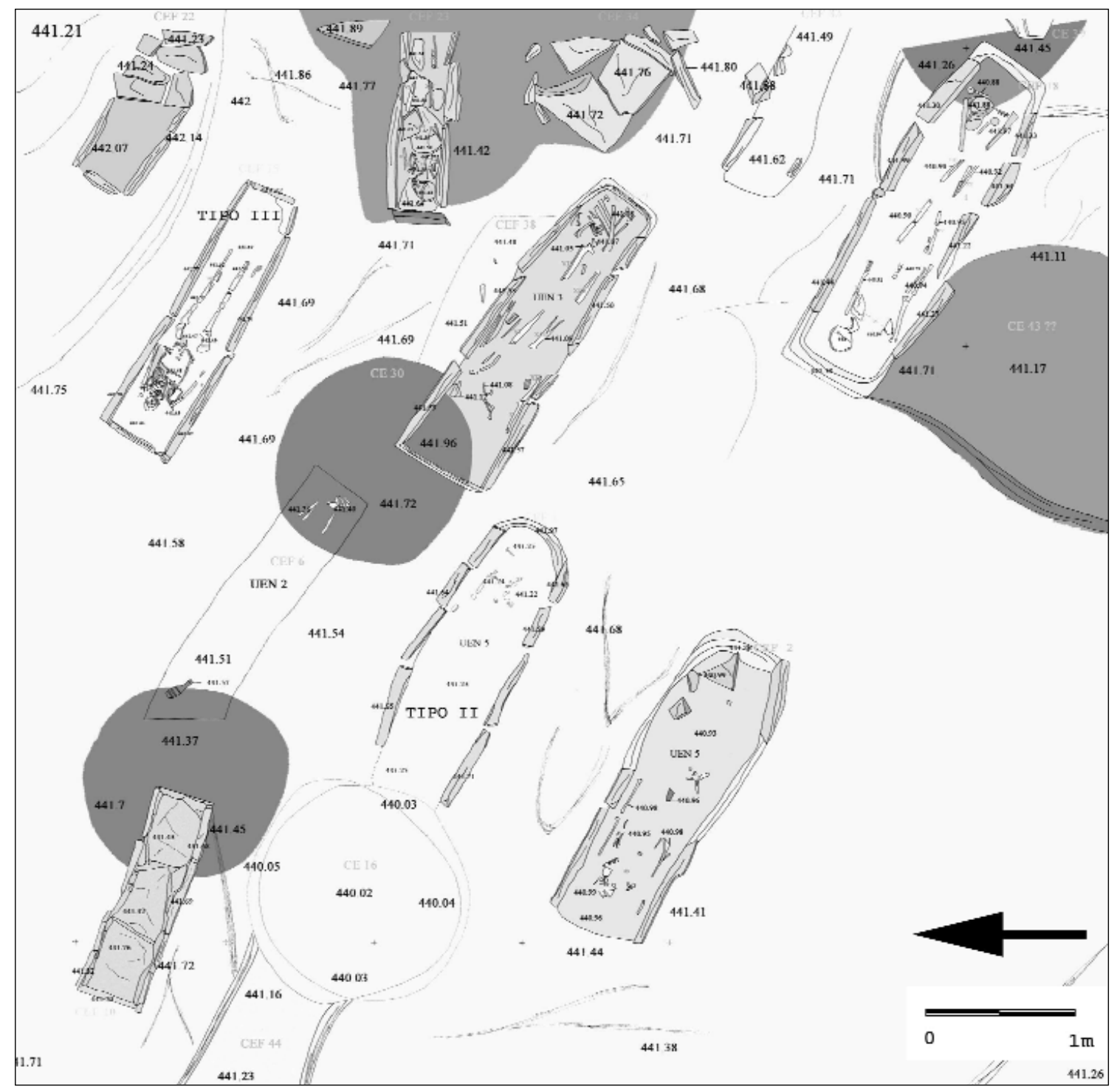

Fig. 3. Corte 7. Planta 2. Interior de las sepulturas

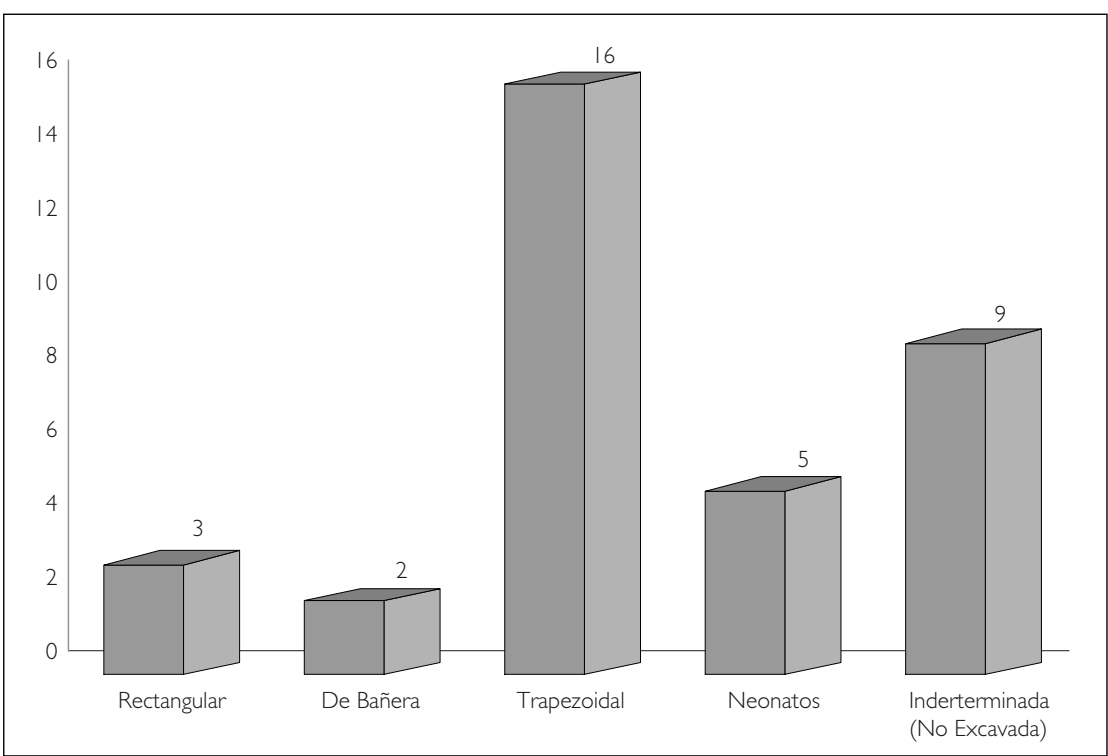

Fig. 4. Tipología formal de las sepulturas 


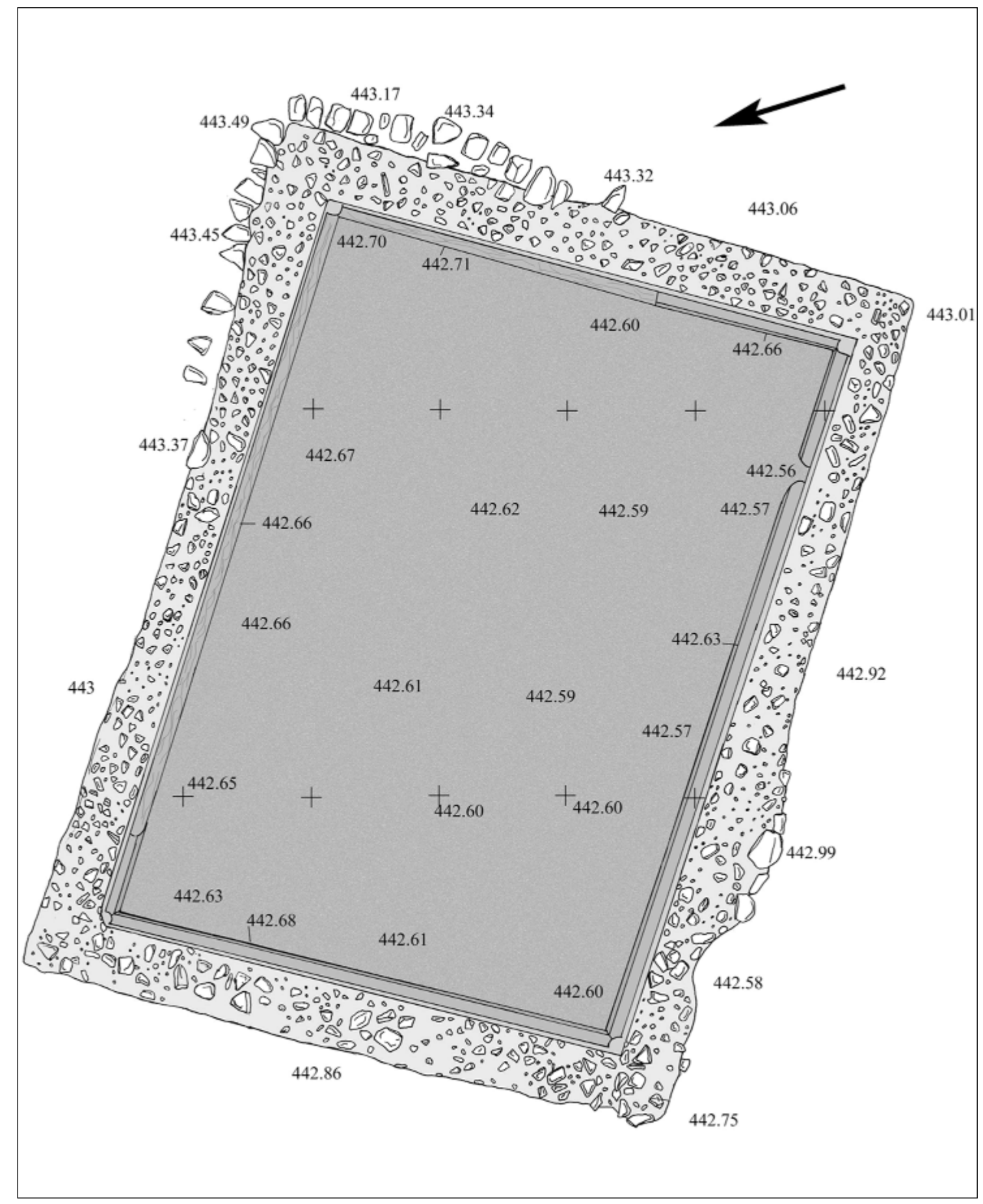

Fig. 5. Corte 6. Planta final. Alberca Romana 


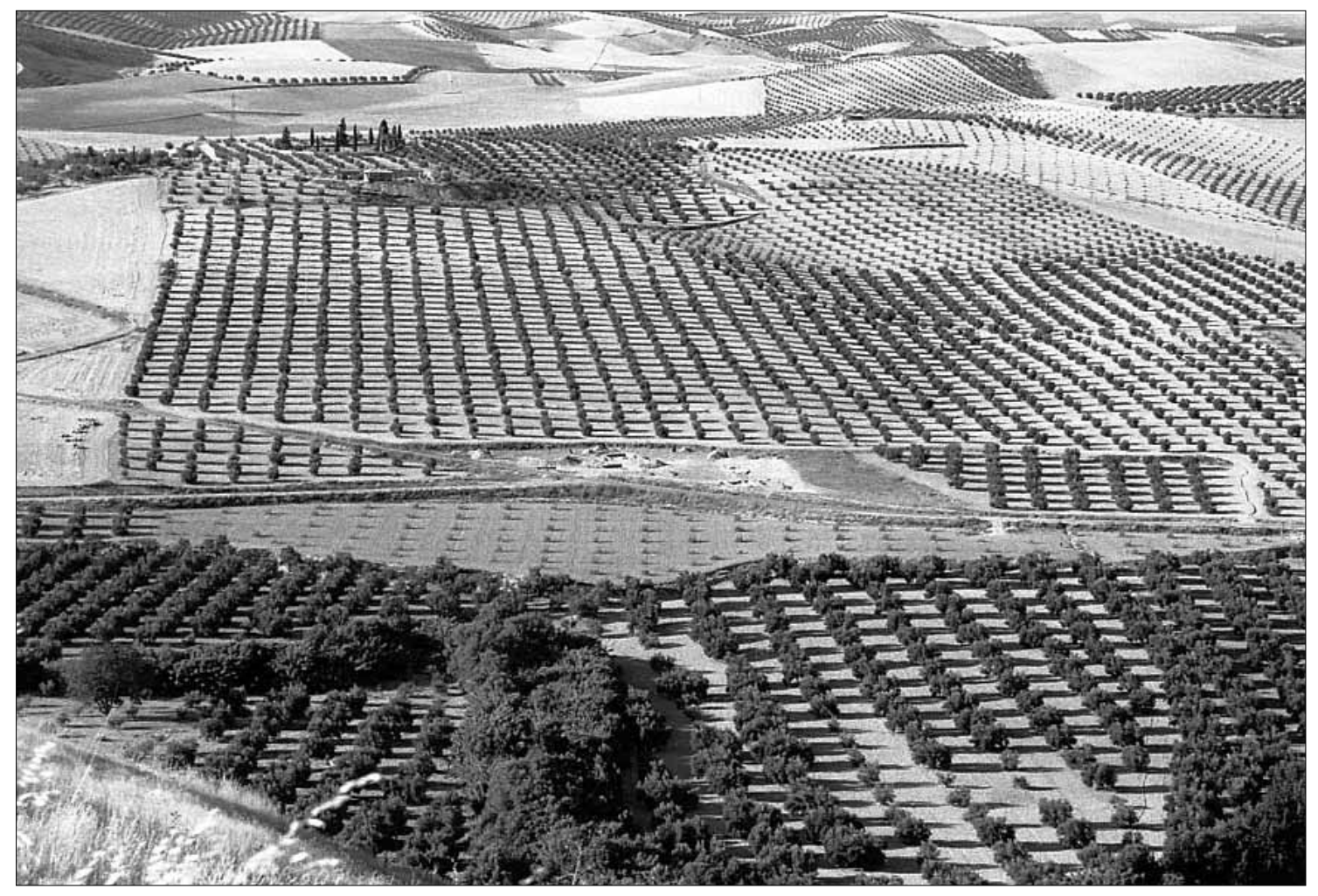

Lam. I. Vista general de la parcela

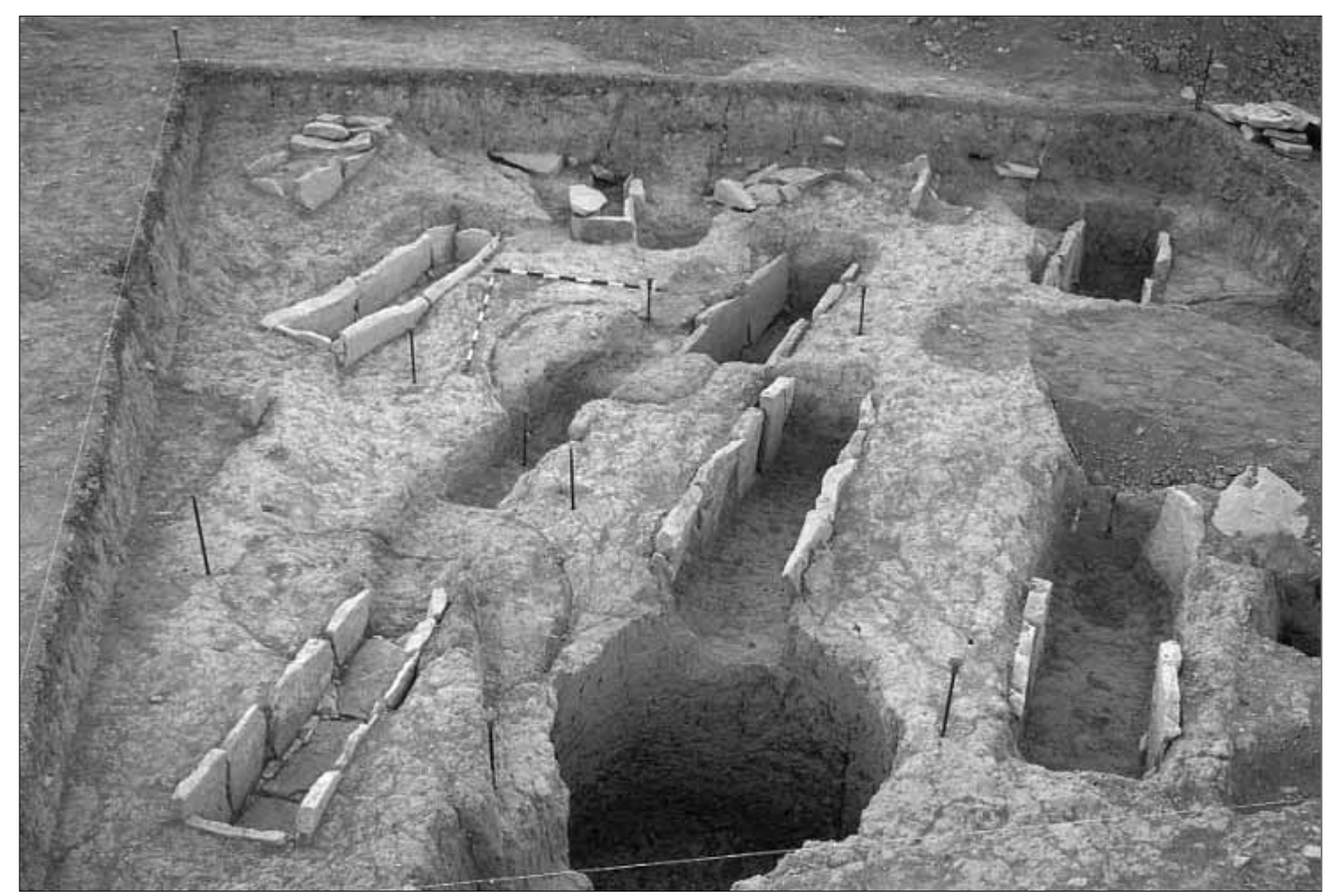

Lam. 2. Vista general del corte 7 


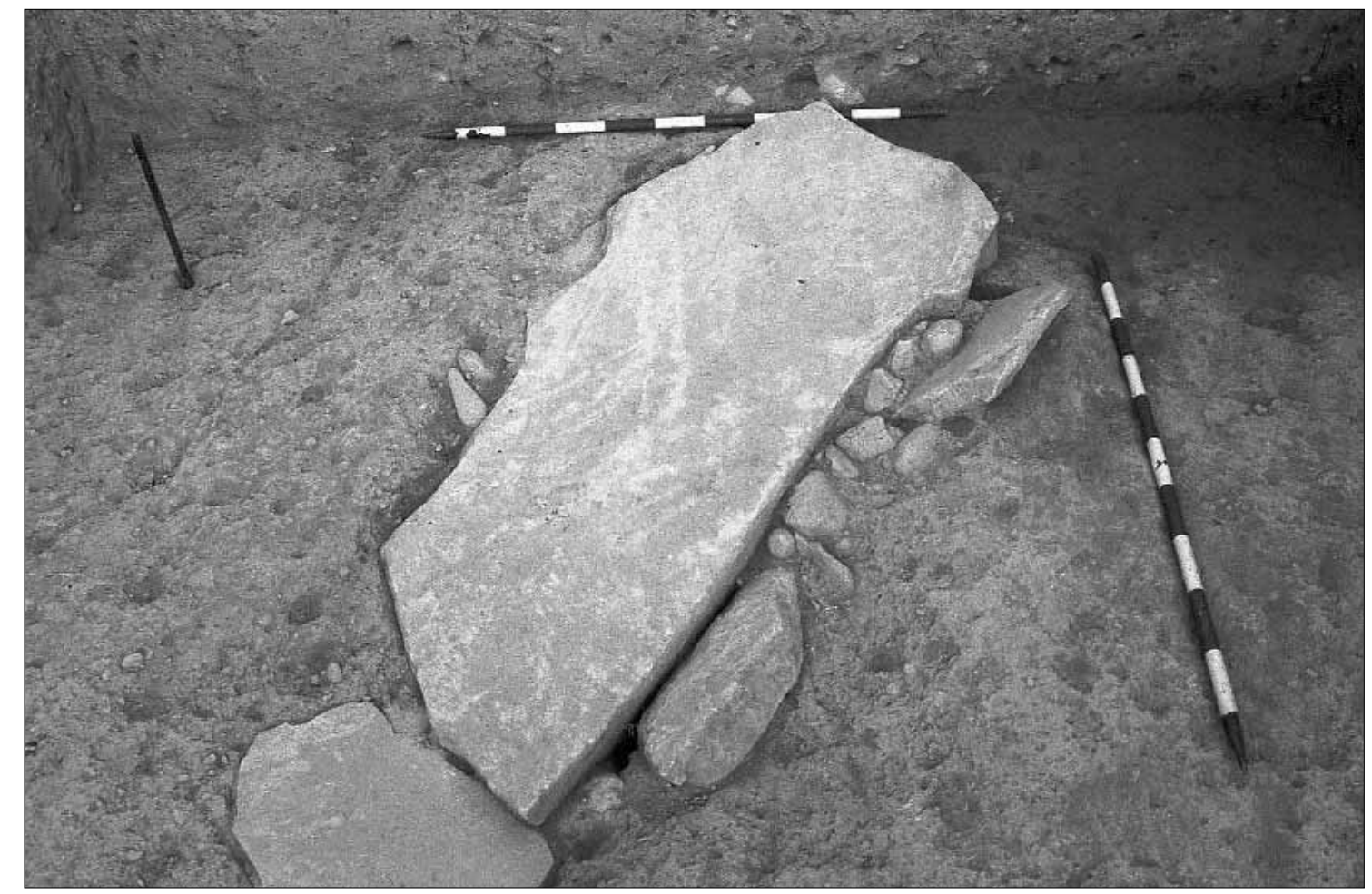

Lam. 3. Primera cubierta de la sepultura 8

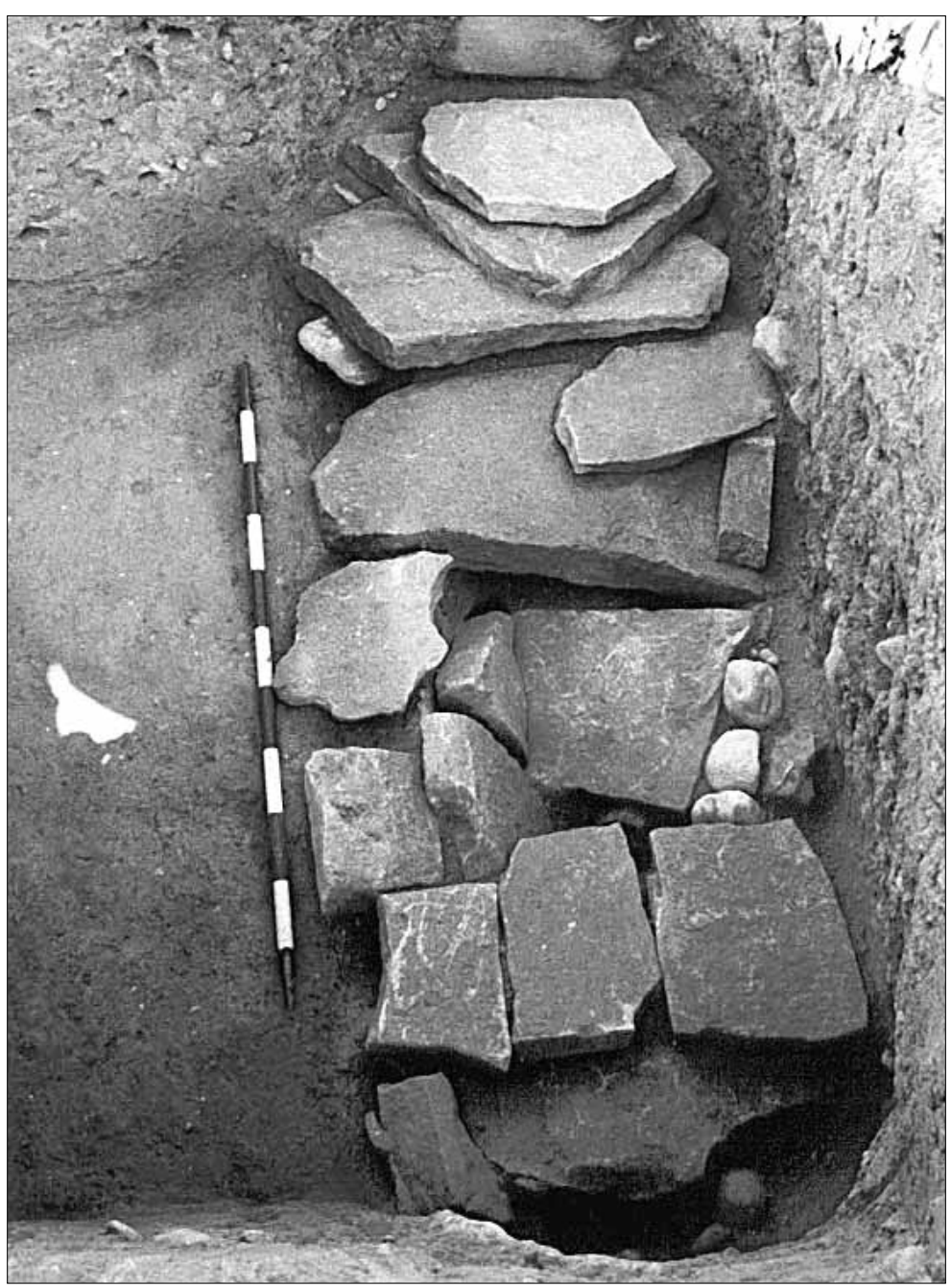

Lam. 4. Segunda cubierta de la sepultura 8 


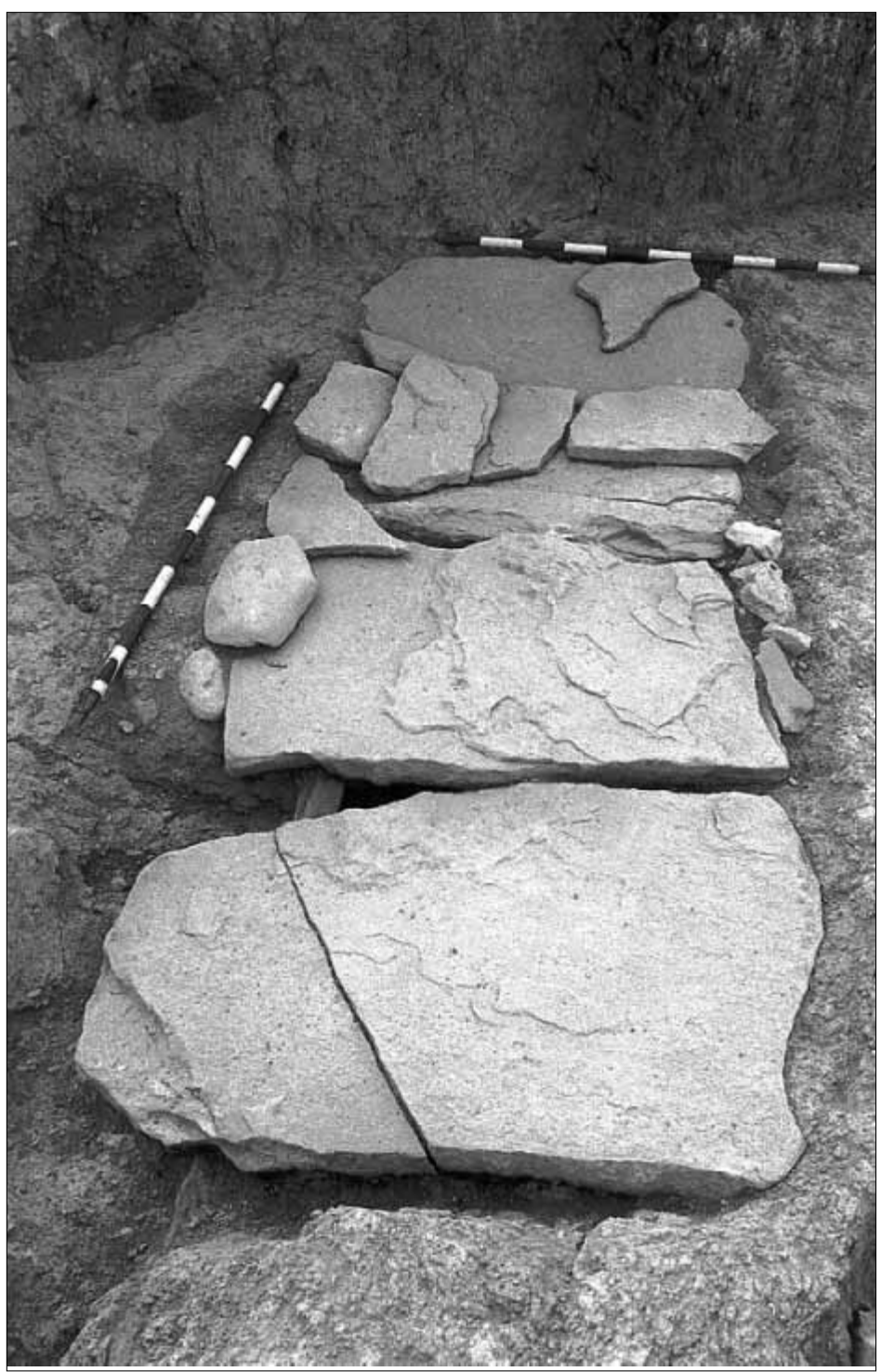

Lam. 5. Cubierta de la sepultura 9 
Lam. 6. Interior de la sepultura 9. Reutilización

Lam. 7. Interior de la sepultura 7. Sepultura 13 (neonato)
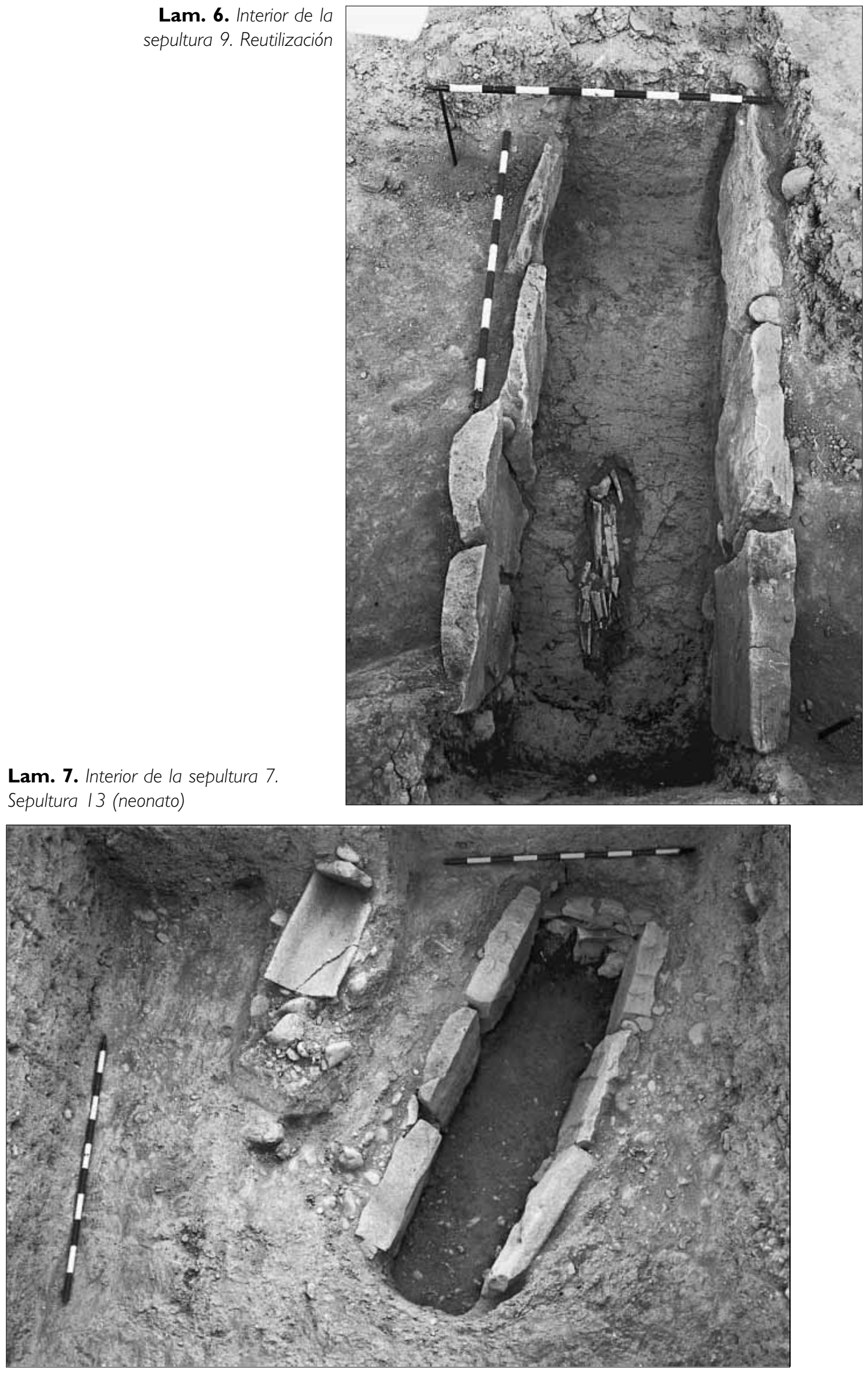


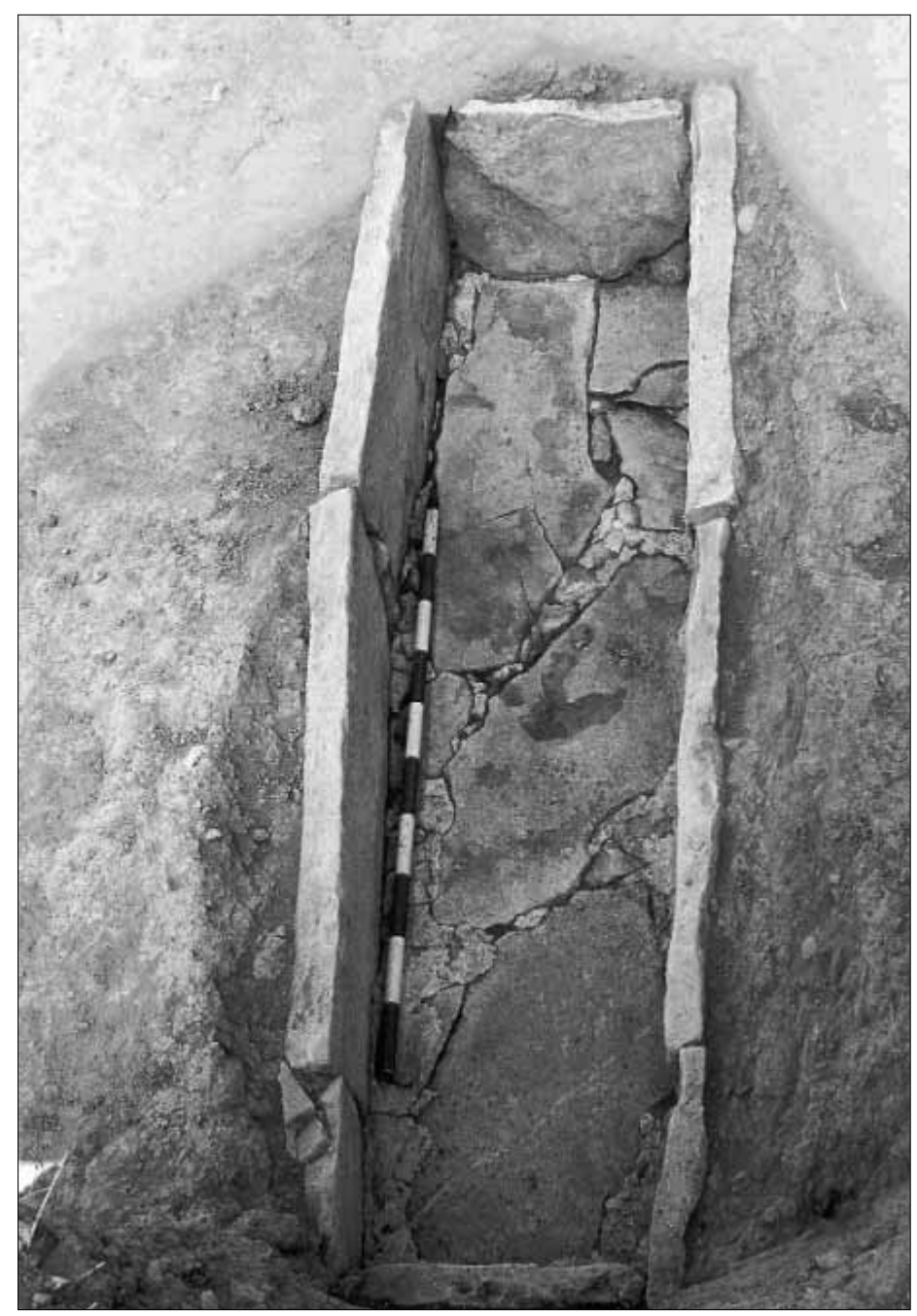

Lam. 8. Sepultura 15

Lam. 9. Vista general

de la alberca romana

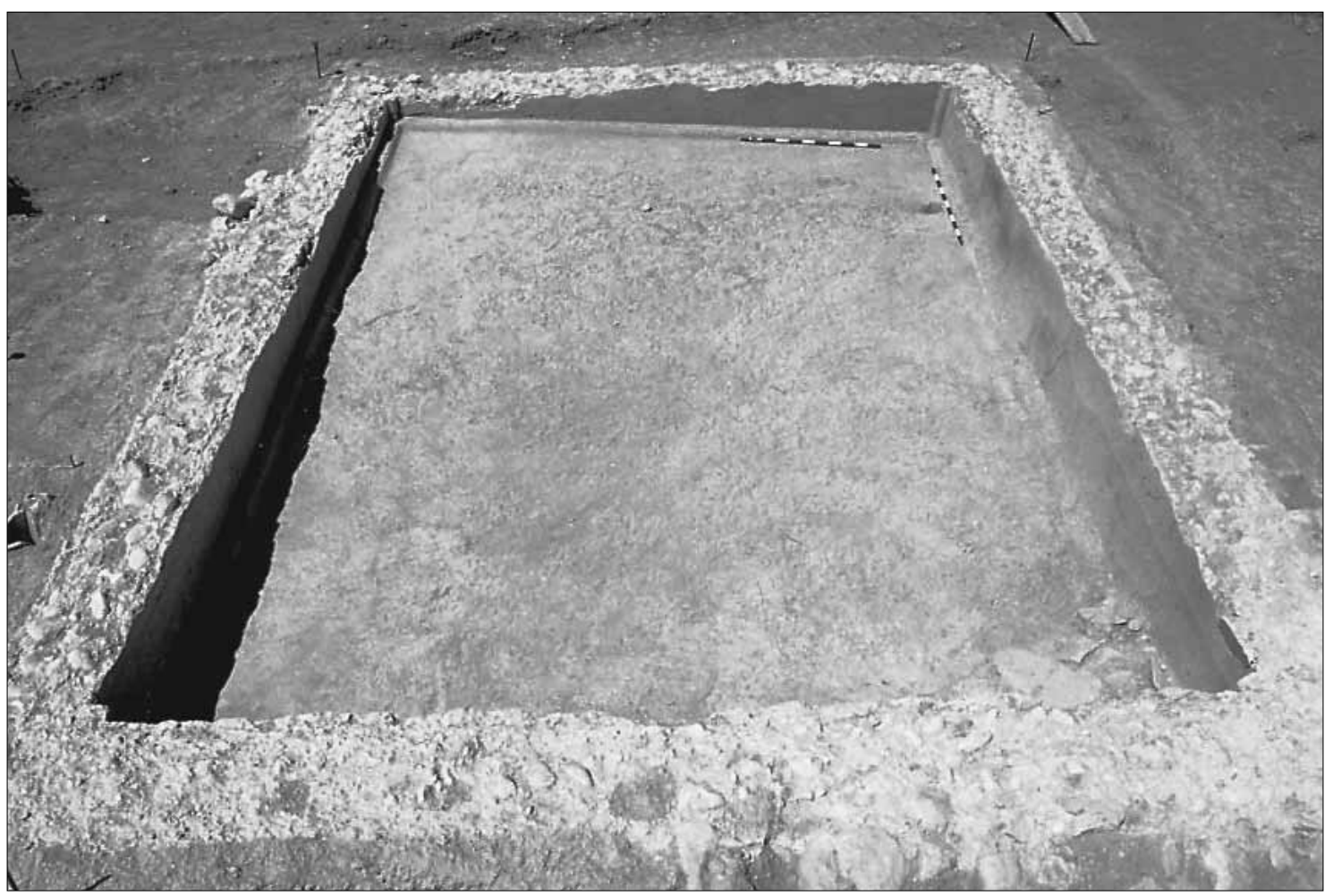



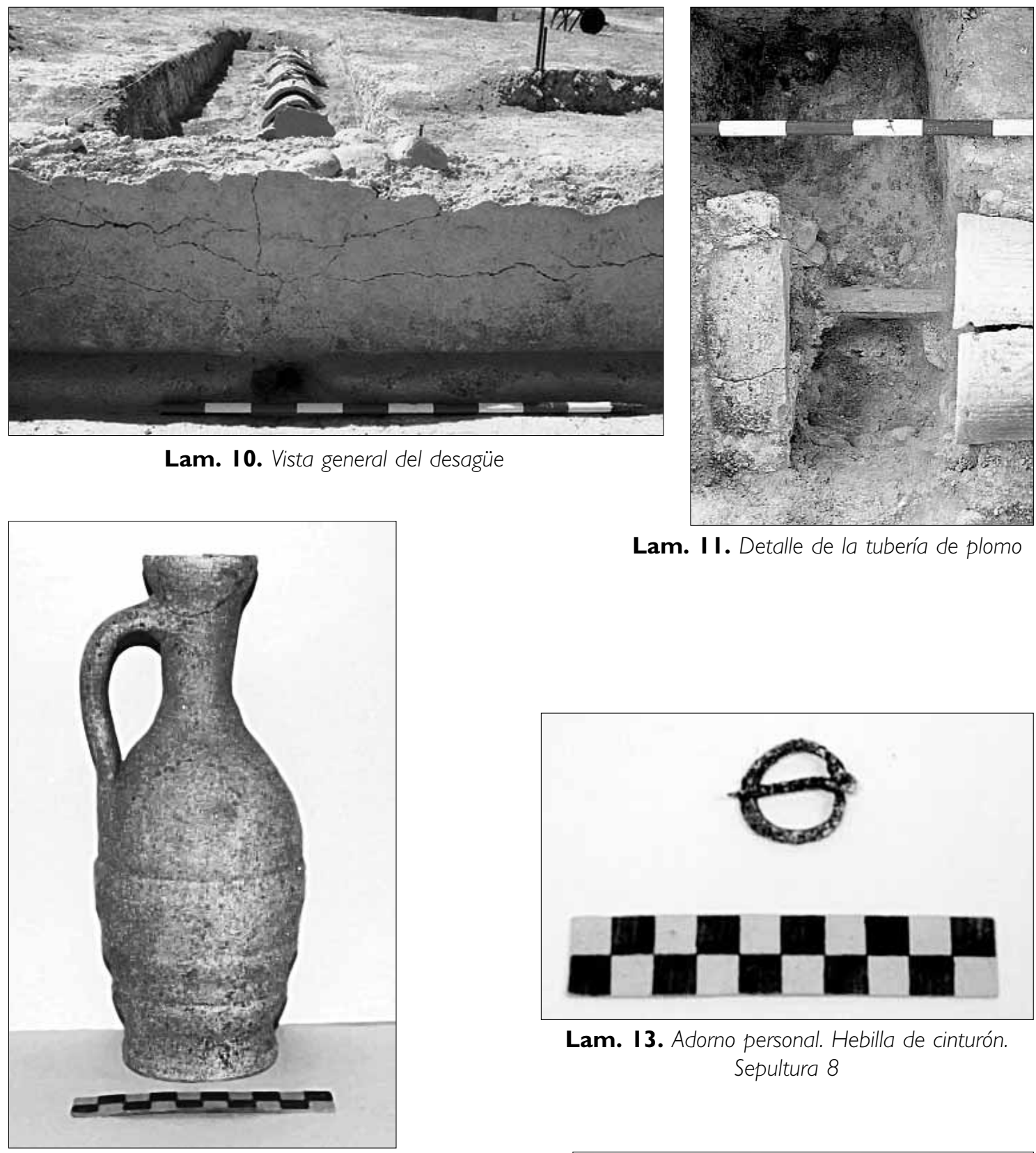

Lam. I I. Detalle de la tubería de plomo

Lam. I 2. Depósito ritual. Sepultura 6

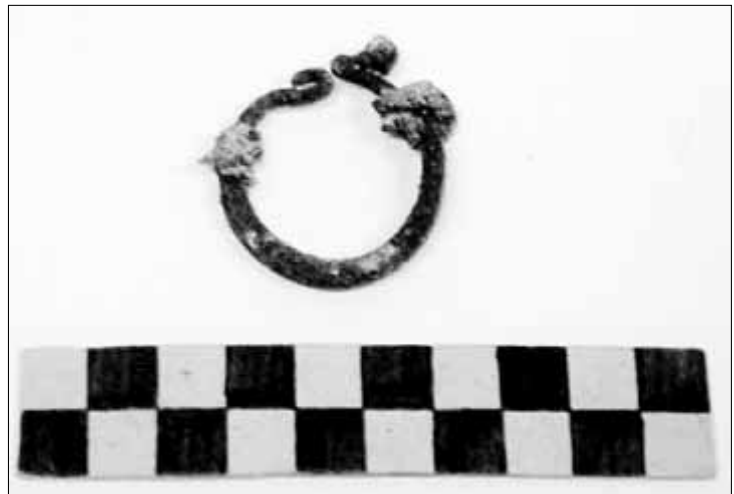

Lam. I4. Adorno personal. Brazalete. Sepultura 8

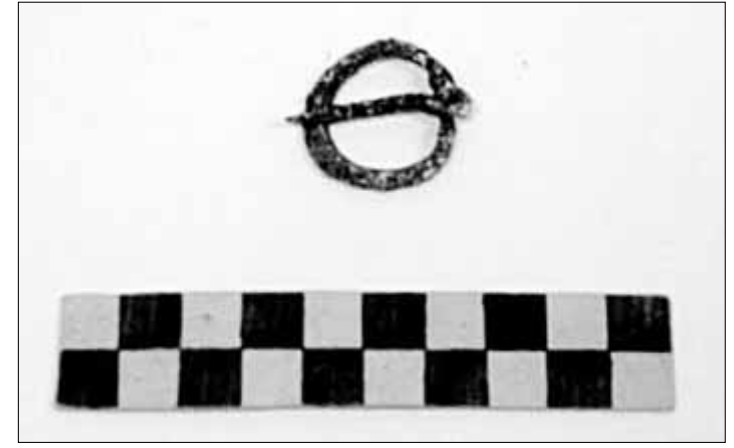

Lam. I3. Adorno personal. Hebilla de cinturón. Sepultura 8

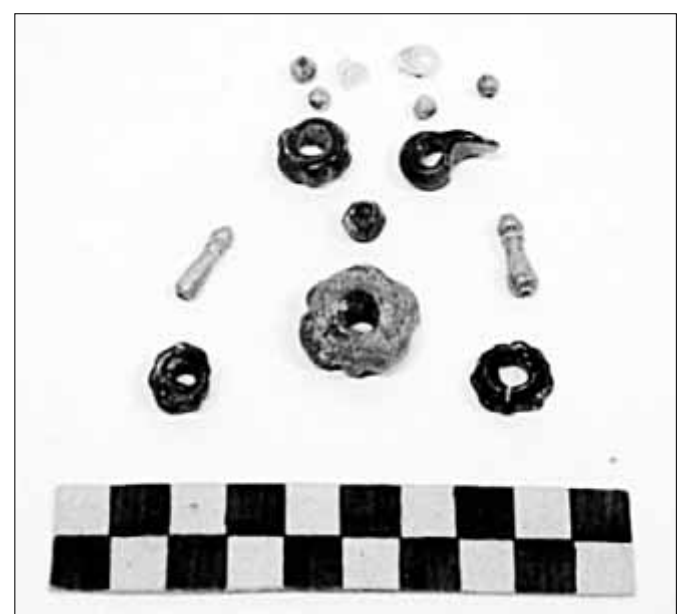

Lam. I5. Adorno personal. Cuentas de collar. Sepultura 1 